\title{
The Mechanism of Peritoneal Fibrosis in Peritoneal Dialysis
}

\author{
Akira Onishi, Yoshiyuki Morishita*, Shigeaki Muto and Eiji Kusano
}

Division of Nephrology, Department of Medicine, Jichi Medical University, Tochigi, Japan

\begin{abstract}
Peritoneal fibrosis (PF) is a common morphological change in peritoneal dialysis (PD) patients. With the progression of $\mathrm{PF}$, peritoneal membrane function is impaired, which leads to ultrafiltration failure. Furthermore, PF is an essential precursor condition for the development of encapsulating peritoneal sclerosis (EPS), which is the most serious complication of PD. Epithelial-mesenchymal transition (EMT) of peritoneal mesothelial cells (PMCs) plays a crucial role in PF. Transforming growth factor- $\beta_{1}\left(\right.$ TGF- $\left.\beta_{1}\right)$ was thought to be the main regulator of EMT in PMCs. High glucose, hypertonicity, low $\mathrm{pH}$, glucose degradation products and advanced glycation end-products in PD solution were suggested to induce TGF- $\beta_{1}$ production. In addition, chronic inflammation mediated by infiltration of immune cells and peritoneal angiogenesis also play pivotal roles for the progression of PF.
\end{abstract}

\section{Introduction}

Peritoneal dialysis (PD) is a useful renal replacement therapy for end-stage renal disease (ESRD). However, long-term PD leads to peritoneal damage and subsequently to peritoneal fibrosis (PF) [1-3]. PF is associated with ultrafiltration failure, which leads to discontinuation of the PD by the patient [1-3]. Furthermore, PF is a major risk factor for the development of encapsulating peritoneal sclerosis (EPS), which is the most serious complication of PD and considered to be one of the reasons why PD is avoided in ESRD patients [4,5]. The mechanisms of the initiation and progression of PF have been increasingly understood through numerous studies involving basic and clinical research.

\section{The mechanism of PF}

Mechanisms such as epithelial-to-mesenchymal transition (EMT) of peritoneal mesothelial cells (PMCs), chronic inflammation and vascularization are thought to be involved in the initiation and progression of PF (Figure 1).

\section{EMT of PMCs}

EMT is a biological process in which an epithelial cell that interacts with basement membrane is altered into a cell with a mesenchymal phenotype that has enhanced migratory capacity, invasiveness and increased production of extracellular matrix [6]. PMCs express epithelial markers such as E-cadherin, cytokeratin and intercellular adhesion molecule 1 (ICAM-1). During the process of EMT, these epithelial markers are downregulated and mesenchymal markers such as $\alpha$-smooth muscle actin, vimentin and fibronectin are upregulated, leading to a change into mesenchymal-like PMCs [7-11]. The expression of type I collagen and the migratory capacity are enhanced in these transformed PMCs $[9,12]$. Several clinical studies reported that peritoneal tissue samples obtained from PD patients showed the existence of elongated fibroblast-like cells expressing epithelial markers such as cytokeratin and ICAM- 1 in the fibrotic tissue of the submesothelial compact zone $[9,13]$. These results suggested that PMCs changed their phenotype to mesenchymal-like cells via EMT and migrated to the submesothelial zone. Transforming growth factor- $\beta_{1}$ (TGF- $\beta_{1}$ ) plays a central role in EMT of PMCs $[9,14-16]$. When TGF- $\beta_{1}$ binds to its receptors, the signal is transmitted through Smad and nonSmad pathways and then upregulates transcription factor Snail, which is a key regulator of EMT, resulting in the phenotypic changes of PMCs [11,17-19].

\section{Chronic inflammation}

Among inflammatory cells, macrophages are the most abundant in
PD effluents and are considered to play a central role in intraperitoneal chronic inflammation [20,21]. Macrophage infiltration was observed histologically in association with PF [22]. The concentrations of tumor necrosis factor- $\alpha$ (TNF- $\alpha$ ), interleukin (IL)- $1 \beta$ and IL-6, which behaved as proinflammatory cytokines mainly produced by macrophages, were reported to be elevated in PD effluent in PF [23-27]. These cytokines can promote fibroblast proliferation and type I collagen synthesis $[28,29]$.

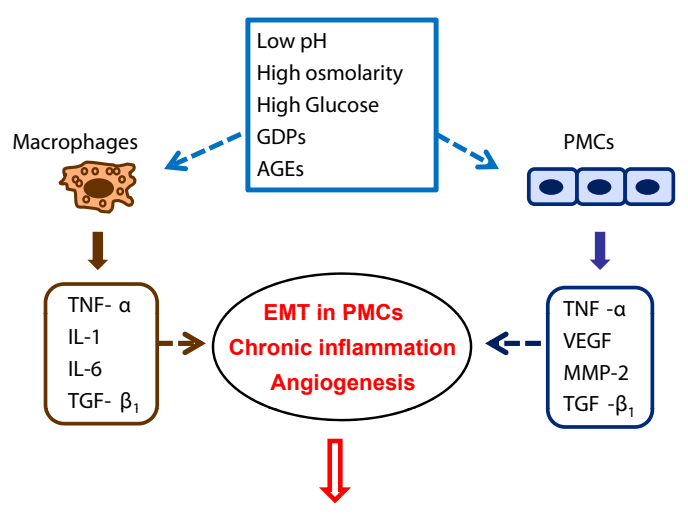

Peritoneal Fibrosis

Figure 1: The mechanisms of peritoneal fibrosis. When stimulated by various factors, peritoneal mesothelial cells (PMCs) and macrophages produce various proinflammatory cytokines and growth factors. These products induce epithelial-mesenchymal transition (EMT) in PMCs, chronic inflammation in the peritoneal cavity and angiogenesis. These processes promote fibroblast proliferation and collagen synthesis, which lead to the progression of peritoneal fibrosis (PF). GDPs: glucose degradation products, AGEs: advanced glycation end-products, TNF- $\alpha$ : tumor necrosis factor-alpha, IL: interleukin, TGF- $\beta_{1}$ : transforming growth factor-beta1, VEGF: vascular endothelial growth factor, MMP-2: matrix metallopeptidase 2, PMCs: peritoneal mesothelial cells, EMT: epithelial-mesenchymal transition.

*Corresponding author: $Y$ Morishita, Division of Nephrology, Department of Medicine, Jichi Medical University, 3311-1, Yakushiji, Shimotsuke-city, Tochigi 3290498, Japan, Tel: 81-285-44-7346; Fax: 81-285-44-4869; E-mail: ymori@jichi.ac.jp

Received October 03, 2011; Accepted December 05, 2011; Published December 07, 2011

Citation: Onishi A, Morishita Y, Muto S, Kusano E (2011) The Mechanism of Peritoneal Fibrosis in Peritoneal Dialysis. J Nephrol Therapeutic S3:002. doi:10.4172/2161-0959.S3-002

Copyright: (c) Onishi A, et al. This is an open-access article distributed under the terms of the Creative Commons Attribution License, which permits unrestricted use, distribution, and reproduction in any medium, provided the original author and source are credited. 
Infiltrated macrophages also contribute to TGF- $\beta_{1}$ production on peritoneum in $\mathrm{PD}$ [30]. Recently, it was reported that the concentration of CC chemokine ligand 18 (CCL18) which was secreted mainly by macrophages in the spent dialysate was high in the PD patients with decreased peritoneal membrane functions, and in those who later developed EPS [31,32]. These results suggested that CCL18 may be directly related to development of PF and EPS. These line of results suggested that chronic inflammation mainly induced by macrophages contributed to the development of PF. A recent study showed that PF was attenuated, at least in part, through the recruitment of regulatory $\mathrm{T}$ cells and the augmentation of an anti-inflammatory cytokine, IL-10 [33]. These results suggested that there are certain roles of lymphocytes other than macrophages on PF. Further studies will be needed to elucidate the role of immune cells for PF.

\section{Peritoneal angiogenesis}

Peritoneal vascular density in PD patients has been reported to be increased in association with increased severity of PF [34]. Submesothelial angiogenesis in a large vascular surface area resulted in elevation of small solute transport, enhancement of glucose absorption and dissipation of the glucose-driven osmotic pressure leading to the reduction of water removal $[1,3]$. Vascular endothelial growth factor (VEGF) acts as a key regulator of angiogenesis, vascular permeability and endothelial cell survival [35]. VEGF was reported to be upregulated by local hypoxia and also possibly by inflammation [36,37]. Local production of VEGF in PMCs was reported to play a central role in peritoneal angiogenesis during PD [38]. Several studies showed that the inhibition of peritoneal angiogenesis by anti-VEGF neutralizing antibody prevented the progression of PF [39-42]. These lines of evidence suggested that angiogenesis promoted the development of PF.

\section{Fibrogenic factors}

Several fibrogenic factors were reported to contribute to the development of PF in PD.

\section{Glucose degradation products (GDPs)}

As a dialysate-side factor, high glucose content is an important fibrogenic factor of the peritoneum on PD. High glucose induces the production of TGF- $\beta_{1}$ [7]. Furthermore, glucose degradation products (GDPs) such as methylglyoxal, glyoxal, formaldehyde and 3-deoxyglucosone (3-DG) from glucose are thought to be factors that strongly induce PF. The glucose is degraded to GDPs during heat sterilization and storage. GDPs have been reported to inhibit proliferation and induce EMT on PMCs via upregulation of TGF- $\beta_{1}$ signaling $[11,43]$. GDPs also promote cytokine release and superoxide radical generation of macrophages and blood polymorphonuclear cells leading to peritoneal injury. Intraperitoneal administration of dialysate including GDP leads to PF in animal models [11]. Furthermore, GDPs are precursors of advanced glycation end-products (AGEs), which are important inducers of PF as described below [44].

\section{Advanced glycation end-products (AGEs)}

AGEs are formed by non-enzymatic glycation between reducing sugars and proteins, lipids and nucleic acids [45]. AGEs are considered to take part in the remodeling and fibrosis of the peritoneum when they interact with their receptors. The receptor of AGE (RAGE) was expressed by PMCs in the submesothelial layer. The accumulation of AGEs is recognized in peritoneal mesothelial and submesothelial layers in PD patients, especially with low ultrafiltration [7,46,47]. In PD patients, since highly concentrated glucose solution is infused into the peritoneal cavity in the long term, the formation of AGEs from GDPs in the peritoneum could be accelerated $[48,49]$. In subnephrectomized rats, AGEs accumulation was observed in fibrotic peritoneum along with the expression of TGF- $\beta_{1}$, and the administration of anti-RAGE antibody was found to prevent $\mathrm{PF}$ as well as the upregulation of TGF- $\beta_{1}$ [50]. Furthermore, PF was not promoted by the exposure to GDP-containing PD fluid in RAGE-deficient mice [51]. These lines of evidence suggested that PF was dependent, at least in part, on AGEsRAGE interaction.

\section{Hypertonicity of dialysate}

Hypertonicity of dialysate is also considered to be a factor that induces PF. Osmotic agents such as glucose, mannitol and glycerol inhibit the growth and stimulate the secretion of lactate dehydrogenase, which reflects cytotoxicity and TGF- $\beta_{1}$ production to induce EMT in PMCs [7]. Low-pH dialysis solution also induced PMC damage [52]. Intraperitoneal injection of acidic dialysate induced $\mathrm{PF}$ in animal models [53]. It was reported that neutral $\mathrm{pH}$ and low-GDP dialysate was less inductive of the progression of PF than conventional dialysate in an animal model [54]. Several clinical studies showed that neutral PD solution with low GDP is superior to conventional solution in terms of biocompatibility and survival in PD patients [44,55,56].

\section{Other fibrogenic factors}

As a patient-side factor, long-term PD treatment is the most representative risk factor for PF. Peritoneal thickness has been reported to increase depending on the duration of PD [46]. Repeated exposure to dialysis fluid with the factors mentioned below might be one of the main causes of PF. The complication of diabetes mellitus is liable to promote PF progression [46]. The mechanism for this may be related mainly to the accumulation of AGEs in diabetic patients. Some clinical studies have revealed that low residual renal function is also associated with high risk of EPS, suggesting that uremia has some influence on the progression of PF $[2,46]$. Not only long-term PD patients but also predialysis uremic patients show increased peritoneal thickness [46]. The accumulation of AGEs is considered to promote peritoneal thickening with fibrosis in a uremic condition [46].

\section{Potential strategy for the prevention and treatment of PF}

Since TGF- $\beta_{1}$ plays a central role in the pathogenesis of PF, it can be a good target for the prevention and treatment of PF. Blockade of TGF- $\beta_{1}$ signaling using anti-TGF- $\beta_{1}$ neutralizing antibody inhibited EMT-like changes in cultured PMCs [7]. Smad7 is a molecule that inhibits TGF- $\beta_{1}$ signaling. Smad7 gene transfer to the peritoneum attenuated PF induced by high-glucose-containing dialysis fluid in an animal model [57]. Similarly, it was reported that the administration of TGF- $\beta_{1}$-blocking peptide attenuated the PF in an animal model [58]. These lines of evidence suggested that the therapy that targets TGF- $\beta$, signaling may be a powerful option in the treatment of PF. Several studies reported therapies targeting the AGEs and RAGE for the treatment of PF. An anti-AGEs reagent, benfotiamine, suppressed the progression of PF partly through the reduction of AGEs accumulation [59]. The administration of anti-RAGE antibody suppressed TGF- $\beta_{1}$ production in the peritoneum and attenuated PF [50]. These lines of evidence suggested that therapy that targets AGEs and RAGE may be a powerful option in the treatment of PF. 
Citation: Onishi A, Morishita Y, Muto S, Kusano E (2011) The Mechanism of Peritoneal Fibrosis in Peritoneal Dialysis. J Nephrol Therapeutic S3:002. doi:10.4172/2161-0959.S3-002

Page 3 of 4

\section{References}

1. Ronco C, Feriani M, Chiaramonte S, Brendolan A, Bragantini L, et al. (1990) Pathophysiology of ultrafiltration in peritoneal dialysis. Perit Dial Int 10: 119126.

2. Lambie ML, John B, Mushahar L, Huckvale C, Davies SJ (2010) The peritoneal osmotic conductance is low well before the diagnosis of encapsulating peritoneal sclerosis is made. Kidney Int 78: 611-618.

3. Margetts PJ, Churchill DN (2002) Acquired ultrafiltration dysfunction in peritoneal dialysis patients. J Am Soc Nephrol 13: 2787-2794.

4. Miyazaki M, Yuzawa $Y(2005)$ The role of peritoneal fibrosis in encapsulating peritoneal sclerosis. Perit Dial Int 25 Suppl 4: 48-56.

5. Honda K, Oda H (2005) Pathology of encapsulating peritoneal sclerosis. Perit Dial Int 25 Suppl 4: 19-29.

6. Kalluri R, Weinberg RA (2009) The basics of epithelial-mesenchymal transition. $\mathrm{J}$ Clin Invest 119: 1420-1428.

7. Ito T, Yorioka N, Yamamoto M, Kataoka K, Yamakido M (2000) Effect of glucose on intercellular junctions of cultured human peritoneal mesothelial cells. J Am Soc Nephrol 11: 1969-1979.

8. Breborowicz A, Breborowicz M, Oreopoulos DG (2003) Glucose-induced changes in the phenotype of human peritoneal mesothelial cells: effect of L-2oxothiazolidine carboxylic acid. Am J Nephrol 23: 471-476.

9. Yanez-Mo M, Lara-Pezzi E, Selgas R, Ramirez-Huesca M, DominguezJimenez C, et al. (2003) Peritoneal dialysis and epithelial-to-mesenchymal transition of mesothelial cells. N Engl J Med 348: 403-413.

10. Aroeira LS, Loureiro J, Gonzalez-Mateo GT, Fernandez-Millara V, del Peso G, et al. (2008) Characterization of epithelial-to-mesenchymal transition of mesothelial cells in a mouse model of chronic peritoneal exposure to high glucose dialysate. Perit Dial Int 28 Suppl 5: 29-33.

11. Hirahara I, Ishibashi Y, Kaname S, Kusano E, Fujita T (2009) Methylglyoxal induces peritoneal thickening by mesenchymal-like mesothelial cells in rats. Nephrol Dial Transplant 24: 437-447.

12. Jimenez-Heffernan JA, Aguilera A, Aroeira LS, Lara-Pezzi E, Bajo MA, et al. (2004) Immunohistochemical characterization of fibroblast subpopulations in normal peritoneal tissue and in peritoneal dialysis-induced fibrosis. Virchows Arch 444: 247-256.

13. Del Peso G, Jimenez-Heffernan JA, Bajo MA, Aroeira LS, Aguilera A, et al (2008) Epithelial-to-mesenchymal transition of mesothelial cells is an early event during peritoneal dialysis and is associated with high peritoneal transport. Kidney Int Supp I: 26-33.

14. Grotendorst GR, Rahmanie H, Duncan MR (2004) Combinatorial signaling pathways determine fibroblast proliferation and myofibroblast differentiation. FASEB J 18: 469-479.

15. Fan JM, Ng YY, Hill PA, Nikolic-Paterson DJ, Mu W, et al. (1999) Transforming growth factor-beta regulates tubular epithelial-myofibroblast transdifferentiation in vitro. Kidney Int 56: 1455-1467.

16. Margetts PJ, Bonniaud P, Liu L, Hoff CM, Holmes CJ, et al. (2005) Transien overexpression of TGF-\{beta\}1 induces epithelial mesenchymal transition in the rodent peritoneum. J Am Soc Nephrol 16: 425-436.

17. Offner FA, Feichtinger H, Stadlmann S, Obrist P, Marth C, et al. (1996) Transforming growth factor-beta synthesis by human peritoneal mesothelial cells. Induction by interleukin-1. Am J Pathol 148: 1679-1688.

18. Loureiro J, Schilte M, Aguilera A, Albar-Vizcaino P, Ramirez-Huesca M, et al. (2010) BMP-7 blocks mesenchymal conversion of mesothelial cells and prevents peritoneal damage induced by dialysis fluid exposure. Nephrol Dial Transplant 25: 1098-1108.

19. Peinado H, Quintanilla M, Cano A (2003) Transforming growth factor beta1 induces snail transcription factor in epithelial cell lines: mechanisms for epithelial mesenchymal transitions. J Biol Chem 278: 21113-21123.

20. Sach M, Loetscher P, Burger JA, Knopf HP, Schollmeyer P, et al. (1995) MCP1 levels are elevated in peritonitis fluid from CAPD patients due to secretion by peritoneal macrophages. Adv Perit Dial 11: 19-23.
21. Pajek J, Kveder R, Bren A, Gucek A, Ihan A, et al. (2008) Short-term effects of a new bicarbonate/lactate-buffered and conventional peritoneal dialysis fluid on peritoneal and systemic inflammation in CAPD patients: a randomized controlled study. Perit Dial Int 28: 44-52.

22. Garosi G, Di Paolo N (2001) Morphological aspects of peritoneal sclerosis. J Nephrol 14 Suppl 4: 30-38

23. Fujimori A, Naito H, Miyazaki T, Azuma M, Hashimoto S, et al. (1996) Elevation of interleukin 6 in the dialysate reflects peritoneal stimuli and deterioration of peritoneal function. Nephron 74: 471-472.

24. Carozzi S, Nasini MG, Ravera M, Sanna A, Tirotta A, et al. (1997) Peritonea dialysis effluent, cytokine levels, and peritoneal mesothelial cell viability in CAPD: a possible relationship. Adv Perit Dial 13: 7-12

25. Lai KN, Lai KB, Lam CW, Chan TM, Li FK, et al. (2000) Changes of cytokine profiles during peritonitis in patients on continuous ambulatory peritoneal dialysis. Am J Kidney Dis 35: 644-652.

26. Maksic D, Vasilijic S, Colic M, Stankovic-Popovic V, Bokonjic D (2009) Systemic and intraperitoneal proinflammatory cytokine profiles in patients on continuous ambulatory peritoneal dialysis. Adv Perit Dial 25: 50-55.

27. Kawanishi H, Fujimori A, Tsuchida K, Takemoto Y, Tomo T, et al. (2005) Markers in peritoneal effluent for withdrawal from peritoneal dialysis: multicenter prospective study in Japan. Adv Perit Dial 21: 134-138.

28. Bachus KE, Doty E, Haney AF, Weinberg JB (1995) Differential effects of interleukin-1 alpha, tumor necrosis factor-alpha, indomethacin, hydrocortisone and macrophage co-culture on the proliferation of human fibroblasts and peritoneal mesothelial cells. J Soc Gynecol Investig 2: 636-642.

29. Cunliffe IA, Richardson PS, Rees RC, Rennie IG (1995) Effect of TNF, IL-1, and IL-6 on the proliferation of human Tenon's capsule fibroblasts in tissue culture. $\mathrm{Br} \mathrm{J}$ Ophthalmol 79: 590-595.

30. Wang T, Ghen YG, Ye RG, Mai WY, Zhen ZH, et al. (1995) Enhanced expression of TGF-beta 1 by peritoneal macrophages in CAPD patients. Adv Perit Dial 11: 11-14

31. Ahmad S, North BV, Qureshi A, Malik A, Bhangal G, et al. (2010) CCL18 in peritoneal dialysis patients and encapsulating peritoneal sclerosis. Eur $\mathrm{J}$ Clin Invest 40: 1067-1073.

32. Bellon T, Martinez V, Lucendo B, del Peso G, Castro MJ, et al. (2011) Alternative activation of macrophages in human peritoneum: implications for peritoneal fibrosis. Nephrol Dial Transplant 26: 2995-3005.

33. Sandoval P, Loureiro J, Gonzalez-Mateo G, Perez-Lozano ML, MaldonadoRodriguez A, et al. (2010) PPAR-gamma agonist rosiglitazone protects peritoneal membrane from dialysis fluid-induced damage. Lab Invest 90: 15171532.

34. Williams JD, Craig KJ, Topley N, Von Ruhland C, Fallon M, et al. (2002) Morphologic changes in the peritoneal membrane of patients with renal disease. J Am Soc Nephrol 13: 470-479.

35. Ferrara N, Davis-Smyth T (1997) The biology of vascular endothelial growth factor. Endocr Rev 18: 4-25.

36. Liu Y, Cox SR, Morita T, Kourembanas S (1995) Hypoxia regulates vascula endothelial growth factor gene expression in endothelial cells. Identification of a 5' enhancer. Circ Res 77: 638-643.

37. Griga T, Voigt E, Gretzer B, Brasch F, May B (1999) Increased production of vascular endothelial growth factor by intestinal mucosa of patients with inflammatory bowel disease. Hepatogastroenterology 46: 920-923.

38. Mandl-Weber S, Cohen CD, Haslinger B, Kretzler M, Sitter T (2002) Vascular endothelial growth factor production and regulation in human peritoneal mesothelial cells. Kidney Int 61: 570-578.

39. Margetts PJ, Gyorffy S, Kolb M, Yu L, Hoff CM, et al. (2002) Antiangiogenic and antifibrotic gene therapy in a chronic infusion model of peritoneal dialysis in rats. J Am Soc Nephrol 13: 721-728.

40. Io H, Hamada C, Ro Y, Ito Y, Hirahara I, et al. (2004) Morphologic changes of peritoneum and expression of VEGF in encapsulated peritoneal sclerosis rat models. Kidney Int 65: 1927-1936. 
Citation: Onishi A, Morishita Y, Muto S, Kusano E (2011) The Mechanism of Peritoneal Fibrosis in Peritoneal Dialysis. J Nephrol Therapeutic S3:002. doi:10.4172/2161-0959.S3-002

Page 4 of 4

41. Yoshio Y, Miyazaki M, Abe K, Nishino T, Furusu A, et al. (2004) TNP-470, an angiogenesis inhibitor, suppresses the progression of peritoneal fibrosis in mouse experimental model. Kidney Int 66: 1677-1685.

42. Bozkurt D, Sarsik B, Hur E, Ertilav M, Karaca B, et al. (2011) A novel angiogenesis inhibitor, sunitinib malate, in encapsulating peritoneal sclerosis. J Nephrol 24: 359-365

43. Hirahara I, Kusano E, Yanagiba S, Miyata Y, Ando Y, et al. (2006) Peritoneal injury by methylglyoxal in peritoneal dialysis. Perit Dial Int 26: 380-392.

44. Lee HY, Park HC, Seo BJ, Do JY, Yun SR, et al. (2005) Superior patient survival for continuous ambulatory peritoneal dialysis patients treated with a peritoneal dialysis fluid with neutral $\mathrm{pH}$ and low glucose degradation product concentration (Balance). Perit Dial Int 25: 248-255.

45. DeGroot J (2004) The AGE of the matrix: chemistry, consequence and cure. Curr Opin Pharmacol 4: 301-305.

46. Honda K, Hamada C, Nakayama M, Miyazaki M, Sherif AM, et al. (2008) Impact of uremia, diabetes, and peritoneal dialysis itself on the pathogenesis of peritoneal sclerosis: a quantitative study of peritoneal membrane morphology. Clin J Am Soc Nephrol 3: 720-728.

47. Park MS, Lee HA, Chu WS, Yang DH, Hwang SD (2000) Peritoneal accumulation of AGE and peritoneal membrane permeability. Perit Dial Int 20: 452-460

48. Schalkwijk CG, Posthuma N, ten Brink HJ, ter Wee PM, Teerlink T (1999) Induction of 1,2-dicarbonyl compounds, intermediates in the formation of advanced glycation end-products, during heat-sterilization of glucose-based peritoneal dialysis fluids. Perit Dial Int 19: 325-333.

49. Nakayama M, Sakai A, Numata M, Hosoya T (2003) Hyper-vascular change and formation of advanced glycation endproducts in the peritoneum caused by methylglyoxal and the effect of an anti-oxidant, sodium sulfite. Am J Nephrol 23: 390-394.

50. De Vriese AS, Tilton RG, Mortier S, Lameire NH (2006) Myofibroblast transdifferentiation of mesothelial cells is mediated by RAGE and contributes to peritoneal fibrosis in uraemia. Nephrol Dial Transplant 21: 2549-2555.

51. Schwenger V, Morath C, Salava A, Amann K, Seregin Y, et al. (2006) Damage to the peritoneal membrane by glucose degradation products is mediated by the receptor for advanced glycation end-products. J Am Soc Nephrol 17: 199207

52. Ha H, Yu MR, Choi HN, Cha MK, Kang HS, et al. (2000) Effects of conventional and new peritoneal dialysis solutions on human peritoneal mesothelial cel viability and proliferation. Perit Dial Int 20 Suppl 5: S10-18.

53. Nakamoto H, Imai H, Fukushima R, Ishida Y, Yamanouchi Y, et al. (2008) Role of the renin-angiotensin system in the pathogenesis of peritoneal fibrosis. Perit Dial Int 28 Suppl 3: S83-87.

54. Kim CD, Kwon HM, Park SH, Oh EJ, Kim MH, et al. (2007) Effects of low glucose degradation products peritoneal dialysis fluid on the peritoneal fibrosis and vascularization in a chronic rat model. Ther Apher Dial 11: 56-64.

55. Williams JD, Topley N, Craig KJ, Mackenzie RK, Pischetsrieder M, et al. (2004) The Euro-Balance Trial: the effect of a new biocompatible peritoneal dialysis fluid (balance) on the peritoneal membrane. Kidney Int 66: 408-418.

56. Szeto CC, Chow KM, Lam CW, Leung CB, Kwan BC, et al. (2007) Clinica biocompatibility of a neutral peritoneal dialysis solution with minimal glucosedegradation products--a 1-year randomized control trial. Nephrol Dia Transplant 22: 552-559.

57. Nie J, Dou X, Hao W, Wang X, Peng W, et al. (2007) Smad7 gene transfer inhibits peritoneal fibrosis. Kidney Int 72: 1336-1344.

58. Loureiro J, Aguilera A, Selgas R, Sandoval P, Albar-Vizcaino P, et al. (2011) Blocking TGF-\{beta\}1 Protects the Peritoneal Membrane from DialysateInduced Damage. J Am Soc Nephrol 22: 1682-1695.

59. Kihm LP, Muller-Krebs S, Klein J, Ehrlich G, Mertes L, et al. (2011) Benfotiamine protects against peritoneal and kidney damage in peritoneal dialysis. J Am Soc Nephrol 22: 914-926.
This article was originally published in a special issue, Clinical Nephrology handled by Editor(s). Dr. Samy L Habib, The University of Texas Health Science Center, USA 